\title{
Effect of Silica Fume and Synthetic Fibre Towards the Compressive Strength of Modified Crumb Rubber Cement Mortar
}

\author{
Mohamad Raduan Bin Kabit ${ }^{1, a *}$, Syed Syabil Rahmat Syed Sarkawi ${ }^{2, b}$, \\ MD Abdul Mannan ${ }^{3, \mathrm{c}}$, Johnson Olufemi Adebayo ${ }^{4, \mathrm{~d}}$ \\ ${ }^{1,2,3}$ Department of Civil Engineering, Faculty of Engineering, Universiti Malaysia Sarawak. \\ ${ }^{4}$ School of the Built Environment, Heriot-Watt University. \\ a*kraduan@unimas.my, b55087@siswa.unimas.my, 'mannan@unimas.my, dO.Johnson@hw.ac.uk
}

Keywords: crumb rubber mortar, compressive strength, silica fume, synthetic fiber

\begin{abstract}
Cracking is very common problem in cement mortar. Many past research has explored the prospect of using crumb rubber (CR) to overcome this issue. Different sizes of CR have been tested to measure its effect on the pore structure and mechanical strengths of cement mortar. Hence, this study has further modified the crumb rubber mortar mix by adding silica fume and synthetic fiber to improve its mechanical properties. The experimental results suggested that the optimum silica fume replacement of cement content was 5\%. Hence, for the subsequent experiment with a fixed 5\%silica fume replacement, the highest compressive strength of $26 \mathrm{MPa}$ was achieved with $5 \%$ crumb rubber replacement. Finally, additional $0.1 \%$ of synthetic fiber added the modified crumb rubber mix to reduce the mix brittleness has produced a desirable compressive strength close to the control specimen which was significantly higher than the minimum threshold required by the standard. However, the water content ratio for the modified mortar mix should be further investigated as the present modified crumb rubber mix has lower workability. It is envisaged that the modified crumb rubber mortar mix has a sound potential to mitigate shrinkage cracking in cement mortar.
\end{abstract}

\section{Introduction}

Considerable demand in the automobile use has caused a significant increase in the production of car tires. As a result, excessive amount of used car tires has led to disposal problems and therefore many research have been undertaken to use the material in engineering products such as cement mortar to reduce its adverse environmental impacts. Cement mortar is a common material used in building construction. Shrinkage cracking is very common in cement mortar due to its poor water retention and cohesiveness. It occurs when the water evaporation rate of its surface is faster than the rate of internal bleeding, which resulted in shrinkage stress in mortar. When such stress is larger than its tensile strength, shrinkage cracking will be developed. In some cases, severe shrinkage cracking will lead to weak concrete bonding due to long exposure to low humidity air.

Many studies have used crumb rubber as sand particles replacement to alleviate drying shrinkage in cement mortar. However, inclusion of crumb rubber in mortar mix have negative impacts on the required strength of the modified mix. For example, Pelisser et al. [1] replaced natural sand in mortars with recycled tyre rubber (maximum size $2.4 \mathrm{~mm}$ ) at levels of $0 \%, 20 \%, 40 \%$ and $60 \%$, by volume. The study found that a gradual reduction in the compressive strength as the replacement percentage increases. In another study, the replacement was done differently which replaced natural sand in mortars with shredded rubber (size 2-0) $\mathrm{mm}$ at levels of $5 \%, 10 \%$ and $15 \%$, by volume [2]. Similarly, the study discovered a reduction in the 28 days compressive strength by $9 \%, 35.31 \%$ and $40.28 \%$ respectively.

For flexural strength and modulus of elasticity, the reduction in the modulus of elasticity at the age of 28 days was $11.79 \%, 28.23 \%$ and $31.744 \%$ respectively. With a greater amount of sand replacement, Rashad [3] reported that with the inclusion of $40 \%, 50 \%$ and $60 \%$ rubber as sand particles replacement, the study results indicated reduction in the compressive strength by $77.85 \%, 79.72 \%$ and $88.87 \%$, respectively, while the reduction in the flexural strength was $76.97 \%, 79.56 \%$ and $88.86 \%$, respectively. Meherier et al., [4] found that replacement of sand with crumb rubber of $25 \%$ and $50 \%$ 